\title{
Management of sudden bereavement in the accident and emergency department
}

\author{
M W Cooke, H M Cooke, E E Glucksman
}

\begin{abstract}
Objective-To assess facilities available for the suddenly bereaved in accident and emergency departments and variations in care of bereaved relatives.

Design-Postal questionnaire survey.

Setting-England and Wales.

Subjects-All 98 accident and emergency departments treating over 50000 patients a year, 78 of which replied.

Main outcome measures-Number of departments with specific facilities, staff training, and procedures for dealing with bereavement.

Results-60 hospitals had a specific room for bereaved relatives; the remainder used multipurpose rooms. In 49 hospitals relatives were taken to the room by a nurse with sole responsibility for caring for them. In $\mathbf{4 0}$ hospitals the nurse stayed with the relatives and 66 updated relatives on the patient's condition. Facilities for viewing the body privately were poor, and relatives often had to ask to be left alone. 25 departments gave no written information on bereavement and only four routinely followed up relatives. Further training was requested by staff in 44 departments.
\end{abstract}

Conclusions-Although facilities could be improved, immediate care of relatives is good. Care over subsequent weeks and preparation for this period is invariably inadequate.

\section{Introduction}

In December 1985 the Department of Health and Social Security circulated a notice recommending action in respect of patients dying in hospital. Before this, health service commissioners had upheld several complaints regarding the events surrounding the deaths of patients. The circular instructed health authorities to compile written instructions to be followed when a patient dies. Several authors have described the optimal care of distressed relatives in the accident and emergency department. ${ }^{1.3}$

Compassionate care of bereaved people is of great importance. The aim of those caring for relatives should be to provide support through the early stages of bereavement and build a foundation for recovery. A specific room should be available for distressed relatives, with appropriate facilities and privacy. A trained member of staff should care for the relatives throughout their stay in the department. They should be allowed to see the body and personal, cultural, and religious requests should be respected. All departments should have information regarding particular religious and cultural issues. Verbal and written information should be offered and relatives should be routinely followed up. Information should be available in locally relevant languages. All accident and emergency staff should have regular training in bereavement care.
We conducted this study to discover how far optimal care is achieved in the larger accident and emergency departments in England and Wales.

\section{Methods}

An extensive structured questionnaire was sent to the senior nurses of all 98 accident and emergency departments in England and Wales treating more than 50000 new patients a year. There are about 250 accident and emergency departments in the United Kingdom. The questionnaire was returned anonymously to ensure confidentiality, so non-responders could not be followed up. Questions explored facilities in the relatives' room, care given to the bereaved in the department, and procedures for viewing after death. The procedures for further visits to the hospital, follow up arrangements (including counselling), and systems for informing other health care professionals were assessed. Any additional procedures in the case of a child's death were also investigated.

\section{Results}

We received completed questionnaires from 78 $(80 \%)$ departments. The responses are discussed below.

Facilities-Sixty departments had a specific room for relatives of patients who had had a cardiac arrest or were very seriously injured. The remainder used a multipurpose office or staff room. This room was close to the resuscitation room in only 15 departments, and in 19 relatives had to walk through the waiting room. Table I shows the facilities available in the room.

TABLE $\mathrm{I}-$ Facilities available in relatives' room in accident and emergency departments

\begin{tabular}{lc}
\hline & $\begin{array}{c}\text { No of responding } \\
\text { hospitals }(\mathbf{n}=78)\end{array}$ \\
\hline Tissues & 56 \\
Telephone with outside line & 48 \\
Refreshments & 50 \\
Ashtrays & 58 \\
Toys & 15 \\
Couch & 31 \\
Toilet close by & 44 \\
Washbasin & 32 \\
\hline
\end{tabular}

Staff-In 49 hospitals a specific nurse accompanied the relatives to the room, in 14 a receptionist took them there, and in eight the member of staff varied. The member of staff stayed with the relatives in 40 departments, and most departments (66) updated relatives and often prepared them for the likely outcome. The news of death was conveyed by the doctor in 30 departments, the relatives' nurse in eight, or either of these in 40 . Although a doctor was always accompanied by a nurse, the converse was true in just seven hospitals. In only six cases were students allowed to
Emergency Medicine,

Dudley Road Hospital,

BMF 1992;304: 1207-9 
accompany the nurse or doctor to learn the skills of care of distressed relatives.

Viewing the body-Relatives usually saw the deceased patient in the resuscitation room ( 42 cases), although six units had a private room and 25 a separate cubicle; in only 35 departments did staff consider that the room gave adequate privacy. In 47 hospitals the relatives' nurse accompanied them, but in 31 someone else accompanied them. The body was covered apart from the head in 18 units and a hand was exposed in a further 58. Relatives were given time alone in 69 departments, but only 44 allowed them to remove rings or any special belongings; 14 insisted that relatives sign for these. Forty one departments allowed relatives to see the body of a patient with mutilating facial injuries, and a further 33 would allow this if the relatives were insistent.

Subsequent care-When the relatives were ready to go home 44 departments paid for a taxi if transport was not available and others used voluntary drivers, the police, or social workers. Fifty eight departments routinely told relatives who they could contact that night for advice. This was usually the accident and emergency department (49) but others mentioned the general practitioner (11) or a counselling facility (eight). However, the general practitioner was informed by telephone by only 36 units and by letter by a further 12. Ten departments presumed that the coroner would inform the general practitioner.

Follow up-Once the relatives had left the hospital there was rarely any further contact with the accident and emergency department. Only four departments routinely contacted the relatives. Although in seven departments the consultant was available to discuss postmortem findings, this was generally left to the coroner (40 departments).

Information-Table II summarises the details contained in leaflets given to people in the accident and emergency department. In the case of cot deaths many other professional agencies were contacted including paediatricians by 26 departments, health visitors by 26 , social workers by 24 , counsellors by 14 , and priests by three; a camera was available in 49 departments.

Teaching-In 20 departments there was no teaching for nursing staff. Of those that did provide teaching, 45 gave in house tuition and only seven sent nurses on courses regularly. Only four departments gave medical staff any training. Increased education was requested by nurses in 44 of the units surveyed.

TABLE II - Information contained in leaflets given to bereaved relatives

\begin{tabular}{lc}
\hline & $\begin{array}{c}\text { No of responding } \\
\text { hospitals }(\mathbf{n}=78)\end{array}$ \\
\hline No leaflet given & 25 \\
Registration of death & 22 \\
Telephone numbers for advice & 13 \\
Bereavement and grief information & 5 \\
Support groups & 4 \\
Cot deaths & 16 \\
What to do after $a$ deat $h^{\star}$ & 3
\end{tabular}

${ }^{\star}$ Department of Health leaflet.

Improvements - Table III shows the views of senior nurses in accident and emergency on the most important items to improve the care of bereaved relatives in their departments.

TABLE III-Senior nurse's views of most important actions to improve care of bereaved relatives

\begin{tabular}{lc}
\hline & No of departments \\
\hline Increased training & 44 \\
Improved relatives' room & 13 \\
Access to a bereavement counsellor & 9 \\
Better leaflets for relatives & 8 \\
More time to spend with relatives & 8 \\
\hline
\end{tabular}

\section{Discussion}

Grief after the death of someone close is a natural reaction, although its expression is highly variable. Deaths occurring in the accident and emergency department are mostly unexpected and often cause prolonged grief and psychological morbidity. ${ }^{4}$

Although most relatives are taken to a specific room by a nurse whose sole task is to care for them, many hospitals still use a multipurpose room to which untrained staff take relatives and leave them alone. The room is rarely close to the resuscitation room, and relatives may have the added distress of walking through the waiting room. The rooms available are generally well decorated, lack of money and space limitations being the usual reasons preventing improvement. Most rooms had an ashtray but only 48 had a telephone and only about half had a washbasin or toilet close by. Because deaths in the accident and emergency department are often unexpected parents may have to bring children with them, but toys were available in only a quarter of the rooms.

News of death is still usually given by a doctor. Although relatives show no preference for who breaks the news (D Ewins, J Bryant, Scarborough meeting of British Association of Accident and Emergency Medicine, April, 1991), they usually wish to speak to a doctor at some stage. When a relative is taken to see the body there is invariably a lack of a quiet private space. Relatives were given time alone with the body, although they often had to request this. These results suggest that there is an urgent need for purpose designed rooms for viewing bodies.

We need to encourage both verbal and physical contact in whatever way each person considers appropriate. Unfortunately, many departments allow relatives to see a patient with mutilating injuries only if they insist. Only two hospitals had a mortician on call to prepare the body at any time of day or night. If relatives wish to remove any rings or special belongings this should be allowed. Many are forced to sign for valuables; there seems to be a confusion between hospital regulations and legal requirements. The legal requirement is only a witnessed signature, not necessarily a signature of a relative.

\section{CARE AFTER LEAVING THE DEPARTMENT}

Relatives are usually told that they can contact the department at any time if they are concerned. A member of staff known to the family is not always available but can avoid the awkwardness of having to explain their situation to somebody who then tries to 욱 offer advice without any background information. N King's College Hospital has employed a community liaison worker; one of her roles is to provide continuing support from the department to bereaved relatives.

Only four departments contacted the relatives after they left the hospital. Most departments seem to $\mathrm{C}$ presume that the relatives will contact another organisation if they feel the need. If a department expects the general practitioner to be the source of consolation and $\mathbb{D}$ help it would be expected that they would contact him or her as soon as possible, yet this was not the case in our survey. All departments should telephone the general practitioner at the earliest possible time, as well as sending written confirmation by first class mail.

A study at King's College Hospital (D Ewins, J Bryant, meeting of British Association of Accident and 8 Emergency Medicine, April 1991) has shown that many relatives want some continuing care after a death, but none of them received unsolicited visits from their general practitioners. We agree with Yates et $a l^{3}$ that accident and emergency departments need to integrate their services for the bereaved with those available in the community. Counselling should be 
universally available as it has been shown to reduce psychological morbidity in high risk groups. ${ }^{4}$

Most departments did not know how a relative finds out the result of a necropsy, although this will usually be available from the coroner's officer. It is important that all relatives should have confirmation of the cause of death. Few do, and it is the responsibility of the accident and emergency staff to ensure that this information is communicated to the family either directly or through their general practitioner. In a time of stress relatives may not be able to absorb much oral information. All bereaved relatives should be given written information as well as oral instructions. There are many advice sheets available from national organisations, as well as leaflets produced by individual hospitals. The leaflets sent out by accident and emergency departments were often incomplete (table II).

\section{IMPROVING CARE}

Staff in accident and emergency departments appreciate the severe psychological trauma caused by a cot death. Paediatricians, health visitors, and counsellors are often brought in at an early stage. The body is treated as a loved one rather than an inanimate object, as sometimes occurs with adults, and a photograph is often taken as a final lasting memory. Most departments give parents one of the nationally produced leaflets to help them cope with their bereavement. Should not this level of care be extended to the relatives of all patients dying in accident and emergency departments? The death of an adult is just as traumatic as the death of a child; the sense of loss is just as great.

Most departments commented on the inadequacy felt by staff when dealing with death, grief, and bereavement. Extra training was widely requested; nurses have in house training at many centres, but it is rare for doctors. One third of deaths in hospital occurred within a few hours of arrival in hospital. ${ }^{3}$ All accident and emergency staff should therefore have adequate training in the care of the suddenly bereaved with emphasis placed on communication and counselling skills.

Accident and emergency departments should review the facilities available for the care of bereaved relatives and there should be an agreed policy to ensure optimal treatment of the family. This must include sufficient flexibility to accommodate the variable wishes of the families. Management of bereavement is one of the most difficult and delicate tasks performed in the accident and emergency department. The last memory is the lasting memory. With appropriate facilities, staff, follow up, and training long term morbidity in the family may be prevented and staff will derive more satisfaction from their care.

\footnotetext{
1 McClauchlan CAJ. Handling distressed relatives and breaking bad news. $B M \mathcal{J}$ 1990;301:1145-7.

2 Tachakra SS, Beckett MW. Dealing with death in the accident and emergency department. Brf Accid Emerg Med 1986;1:10-1.

3 Yates DW, Ellison G, McGuiness S. Care of the suddenly bereaved. BMF 1990;301:29-31.

4 Raphael B. Preventative intervention with recently bereaved. Arch Gen Psychiatry 1977;34:1450-4.
}

(Accepted 28 February 1992)

\section{Department of \\ Histopatholoy, Bristol \\ Royal Infirmary, Bristol BS2 8HW \\ Lynn Hirschowitz, senior registrar in histopathology}

Departments of Public Health Medicine and Cytology, Southmead Hospital, Bristol BS10 5NB Angela E Raffle, consultant in public health medicine

Elizabeth F D Mackenzie, consultant cytopathologist

Department of

Epidemiology, Bristol

Medical School, Bristol

BS8 2PR

A O Hughes, senior lecturer in medical statistics

Correspondence to: Dr L Hirschowitz, Bristol Maternity Hospital, Bristol BS2 8EG.

BMf 1992;304:1209-12

\title{
Long term follow up of women with borderline cervical smear test results: effects of age and viral infection on progression to high grade dyskaryosis
}

\author{
Lynn Hirschowitz, Angela E Raffle, Elizabeth F D Mackenzie, A O Hughes
}

\section{Abstract}

Objective-To follow up and assess the significance of borderline change in cervical smears.

Design-Retrospective study of women undergoing routine cervical cytological screening in 1981 .

Setting-Avon Cervical Screening Programme, covering 250000 women in Bristol and Weston super Mare.

Subjects -437 women showing borderline cervical changes in 1981 and 437 age matched controls with normal results in 1981 .

Main outcome measures-Cytological progression to high grade dyskaryosis (cervical intraepithelial neoplasia grade III or invasive carcinoma).

Results-During follow up ranging from 13 to 106 months 98 of the 437 women $(22.4 \%)$ with borderline cytological changes on routine cervical cytology screening had a subsequent smear test showing high grade dyskaryosis compared with three of the 437 women $(0.9 \%)$ in the control group. The risk of progression was greater in women aged 20 to 39 than in those aged 40 and over. Human papillomavirus infection had initially been diagnosed cytologically in 101 of the $437(23 \%)$ women with borderline results. Significantly fewer of these women developed high grade dyskaryosis (13/98 $(13 \%) v 88 / 339(26 \%), \mathrm{p}<0.05)$.

Conclusions-Women with borderline smear test results are at increased risk of developing high grade dyskaryosis, particularly if the borderline changes occur without cytological features of human papil- lomavirus infection. Progression occurs within three years in $\mathbf{5 0 \%}$ of cases, although a linearly increasing risk was sustained over the nine years of follow up and was greatest in women aged 20 to 39. Careful follow up of these women is indicated.

\section{Introduction}

Cytological criteria for diagnosing mild, moderate, or severe dyskaryosis in ceryical smears are well established.' In some cases, however, smears show only minor nuclear abnormalities that could reflect either the effects of inflammation or the potential for neoplastic growth, and these two possibilities cannot be distinguished cytologically. The British Society for Clinical Cytologists recommended that the term borderline be used to describe such smears.

Data from the Avon Cervical Screening Programme have shown a steady annual increase in the number of women whose cervical smears are designated as borderline. In 1981, the first year this result was separately classified in the programme's records, 638 women $(1.5 \%$ of all of those assessed) were diagnosed as having borderline cytological changes. The number of women with borderline results has risen steadily, both in absolute numbers and as a proportion of all smears examined. In 1988 and $1989,4 \cdot 8 \%$ and $4 \cdot 2 \%$ of the women tested had borderline results, and their numbers in both years exceeded 2000 , more than the combined total of women with dyskaryotic smears of all grades. 